\title{
DNA methylation changes in biomarker loci occur early in
}

\section{cancer progression [version 1; peer review: 2 approved]}

\author{
Lukas Vrba (Di)1, Bernard W. Futscher ${ }^{1,2}$ \\ ${ }^{1}$ The University of Arizona Cancer Center, The University of Arizona, Tucson, Arizona, 85724, USA \\ 2Department of Pharmacology \& Toxicology, College of Pharmacy, The University of Arizona, Tucson, Arizona, 85724, USA
}

V1 First published: $16 \operatorname{Dec} 2019, \mathbf{8 : 2 1 0 6}$

https://doi.org/10.12688/f1000research.21584.1

Latest published: 14 Feb 2020, 8:2106

https://doi.org/10.12688/f1000research.21584.2

\section{Abstract}

Tumor-specific DNA methylation can be used for cancer diagnostics and monitoring. We have recently reported a set of DNA methylation biomarkers that can distinguish plasma samples from lung cancer patients versus healthy controls with high sensitivity and specificity. Furthermore, the DNA methylation signal from the biomarker loci detected in plasma samples correlated with tumor size and decreased after surgical resection of lung tumors. In order to determine the timing of DNA methylation of these loci during carcinogenesis and thus the potential of the biomarkers to detect early stages of the disease we analyzed the DNA methylation of the biomarker loci in five precancerous conditions using available data from the GEO database. We found that the DNA methylation of the biomarker loci is gained early in carcinogenesis since most of the precancerous conditions already have biomarker loci hypermethylated. Moreover, these DNA methylation biomarkers are able to distinguish between precancerous lesions with malignant potential and those that stay benign where data is available. Taken together, the biomarkers have the potential to detect the earliest cancer stages; the only limitation to detection of cancer from plasma samples or other liquid biopsies is the timing when tumors start to shed enough DNA into body fluids.

\section{Keywords}

DNA Methylation, Cancer Biomarker, Epigenetics

\section{Open Peer Review}

Approval Status

1 2

version 2

(revision)

14 Feb 2020

version 1

16 Dec 2019

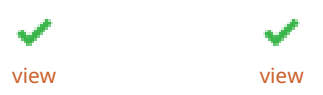

1. Keith D. Robertson, Mayo Clinic, Rochester, USA

2. Judd C. Rice, University of Southern California, Los Angeles, USA

Any reports and responses or comments on the article can be found at the end of the article.

This article is included in the Oncology

gateway. 
Corresponding author: Lukas Vrba (Ivrba@uacc.arizona.edu)

Author roles: Vrba L: Conceptualization, Formal Analysis, Investigation, Methodology, Software, Validation, Visualization, Writing Original Draft Preparation, Writing - Review \& Editing; Futscher BW: Funding Acquisition, Writing - Review \& Editing

Competing interests: $B$. Futscher is a co-founder of DesertDx, LLC

Grant information: This work was supported by the Maynard Chair in Breast Cancer Epigenomics at the University of Arizona Cancer Center and the NIH Cancer Center Support Grant (P30 CA023074).

The funders had no role in study design, data collection and analysis, decision to publish, or preparation of the manuscript.

Copyright: @ 2019 Vrba L and Futscher BW. This is an open access article distributed under the terms of the Creative Commons Attribution License, which permits unrestricted use, distribution, and reproduction in any medium, provided the original work is properly cited.

How to cite this article: Vrba $L$ and Futscher BW. DNA methylation changes in biomarker loci occur early in cancer progression [version 1; peer review: 2 approved] F1000Research 2019, 8:2106 https://doi.org/10.12688/f1000research.21584.1

First published: 16 Dec 2019, 8:2106 https://doi.org/10.12688/f1000research.21584.1 


\section{Introduction}

Tumor cells have fundamentally different DNA methylation profile from normal cells of origin ${ }^{1-4}$. Some of these differences are tumor-specific, i.e. do not occur in any normal cell types, and thus could be used for tumor DNA identification. Since tumors shed DNA into bloodstream or other body fluids ${ }^{5-7}$, the detection of tumor-specific DNA methylation in these liquid biopsies could be utilized for non-invasive cancer diagnostics and monitoring ${ }^{8,9}$. This initiated a search for cancer-specific DNA methylation biomarker loci and analysis of these loci in plasma samples and other liquid biopsies ${ }^{10-12}$. We have previously described a large suite of cancer-specific DNA methylation biomarker loci discovered using TCGA and GEO data from over 10,000 tumor and normal samples ${ }^{13}$. Recently, we developed qPCR amplicons specific for a subset of these biomarker loci designed to detect common carcinoma types and tested them on clinical cfDNA samples from healthy individuals and non-small cell lung cancer (NSCLC) patients. We demonstrated that these biomarkers can distinguish between healthy subjects and NSCLC patients with high sensitivity and specificity ${ }^{14}$. Moreover, in blood samples from lung cancer patients the biomarker DNA methylation signal positively correlates with tumor size ${ }^{14}$. The purpose of the current study was to find how early during carcinogenesis the biomarker loci gain DNA methylation in order to assess their potential as detectors of early stage cancer. To this end, we analyzed DNA methylation of the biomarker loci in publically available data from several precancerous conditions. We found that the biomarker loci gain DNA methylation early in carcinogenesis since they are methylated already in majority precancerous lesions analyzed; in addition, where the data are available, the markers can distinguish lesions with malignant potential from those that stay benign.

\section{Methods}

The DNA methylation data from the Illumina Human Methylation450 platform were downloaded from the GEO database (GEO accessions GSE60185, GSE66313, GSE53051, GSE58999, GSE48684, GSE77954, GSE72872, GSE81334, GSE108123 and GSE39279). These DNA methylation data are presented as beta values - numeric values in interval 0.0-1.0. For unmethylated $\mathrm{CpGs}$ the beta value approaches zero, for fully methylated CpGs beta approaches 1 and for CpGs methylated in a fraction of the sample $0<$ beta $<1$, e.g. a $\mathrm{CpG}$ methylated in $50 \%$ of the sample will have a beta value of approximately 0.5 . All data were analyzed in the $\mathrm{R}$ programming environment, version 3.6.1 $1^{15}$ as follows: The beta values were normalized as described ${ }^{13}$. The normalized beta values for 10 biomarker CpGs (Table $1,{ }^{14}$ ) were used in further analysis. Boxplots were created using the $\mathrm{R}$ function boxplot and the $\mathrm{R}$ library beeswarm,version 0.2.3 Multidimensional scaling (MDS) plots were constructed using the $\mathrm{R}$ function cmdscale on matrices of distances between samples and projected into two dimensions. The ability of the marker set to distinguish between progressive and regressive lung CIS was evaluated using receiver operating characteristic (ROC) analysis on the sums of the beta values from all 10 marker CpG Illumina probes (Table 1). The ROC analysis and AUC calculations were performed using the $\mathrm{R}$ library $\mathrm{pROC}^{16}$, version 1.15.3.

\begin{abstract}
Table 1. List of 10 DNA methylation biomarker loci used in the study. The first column specifies Illumina CpG probe and the second column shows the genomic position of each biomarker CpG.
\end{abstract}

\begin{tabular}{|l|l|}
\hline Illumina CpG.ID & CpG.position (hg19) \\
\hline cg14416371 & chr11:43602847-43602848 \\
\hline cg08189989 & chr2:105459164-105459165 \\
\hline cg00100121 & chr1:169396635-169396636 \\
\hline cg03306374 & chr16:23847325-23847326 \\
\hline cg01419831 & chr2:162283705-162283706 \\
\hline cg25875213 & chr19:38183055-38183056 \\
\hline cg00339556 & chr5:16180048-16180049 \\
\hline cg01893212 & chr7:49813088-49813089 \\
\hline cg14732324 & chr5:528621-528622 \\
\hline cg07302069 & chr7:27196286-27196287 \\
\hline
\end{tabular}

\section{Results and discussion}

We have previously described a set of DNA methylation biomarker loci that are hypermethylated in 10 common carcinoma tumor types and we demonstrated that the level of DNA methylation of these loci can differentiate between plasma samples from lung cancer patients and healthy individuals. To determine the timing of the hypermethylation of these biomarker loci during human carcinogenesis and thus estimate potential of the markers to detect early disease stages we analyzed here the DNA methylation state of the biomarker loci in several premalignant conditions: breast ductal carcinoma in situ (DCIS), colorectal adenomas, Barrett's esophagus (BE), pancreatic intraductal papillary mucinous neoplasms (IPMNs) and lung carcinoma in situ (CIS) using publically available Illumina HumanMethylation450 datasets from the GEO database.

Ductal carcinoma in situ is a precursor of invasive breast carcinoma (IBC). We analyzed DNA methylation of the biomarker loci in normal breast tissue samples, DCIS and IBC from three GEO datasets: GSE60185 ${ }^{17}$, GSE66313 ${ }^{18}$, GSE53051 ${ }^{19}$. The results (Figure 1A) show that the biomarker loci are methylated already in DCIS at about the same level as in IBC. The multidimensional scaling (MDS) plot (Figure 1B) shows DCIS samples scattered among IBC samples, indicating comparable levels of DNA methylation of individual markers, while most of the normal samples form a small cluster on a side of the plot. Furthermore, there is no significant increase in the marker methylation during the progression to metastatic disease, as illustrated by data from a cohort $\left(\mathrm{GSE} 58999^{20}\right)$ of 44 pairs of primary breast tumors and lymph node metastases (Figure 1A).

Colorectal adenomas are the precursor neoplasms to colorectal cancer. We analyzed biomarker loci in normal colorectal tissue, colorectal adenomas, colorectal carcinomas and metastatic colorectal tumors from three GEO datasets: GSE48684 ${ }^{21}$, 
A

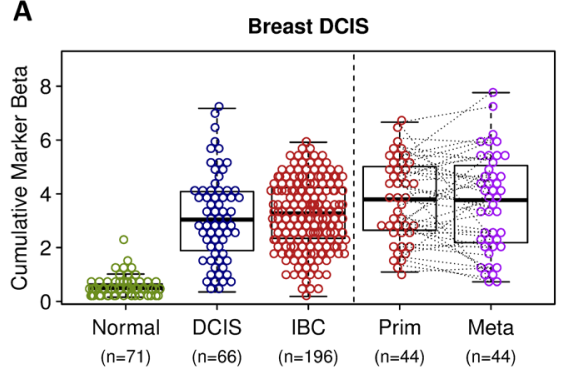

C

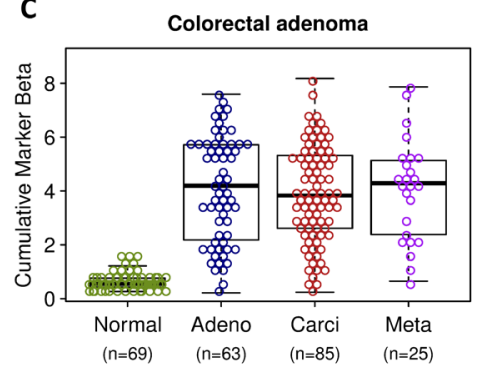

I

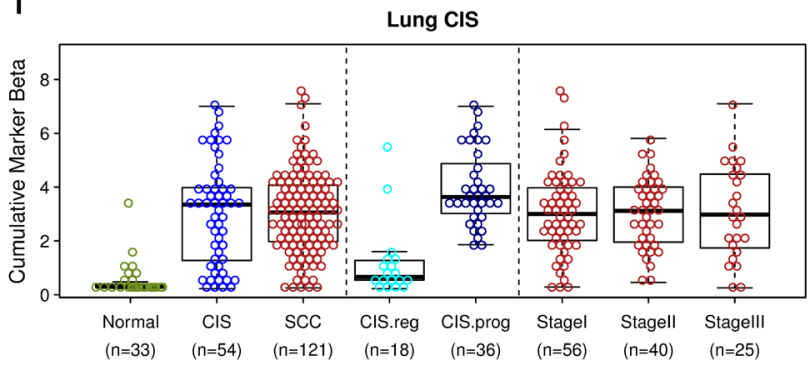

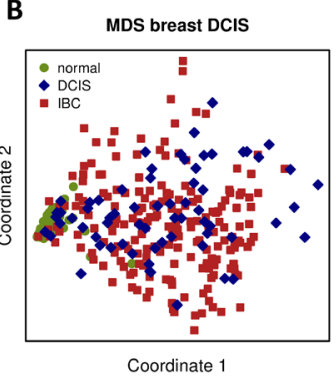

D

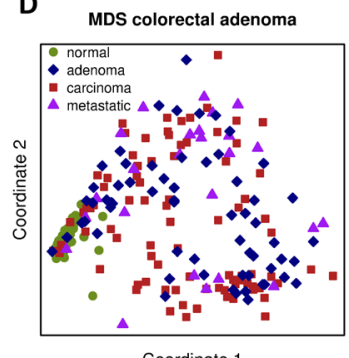

E

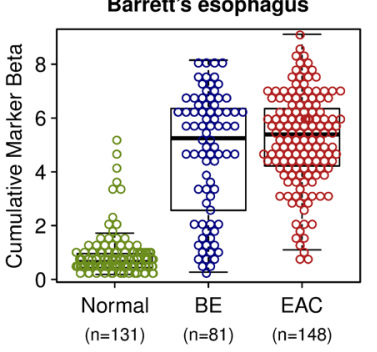

G

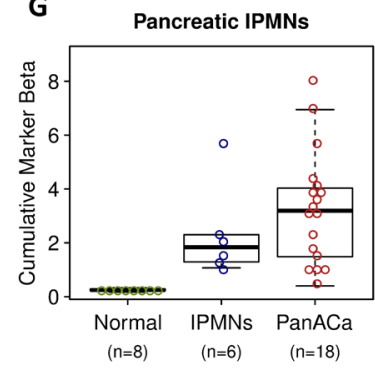

J

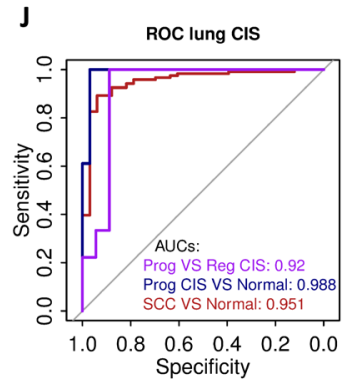

F MDS Barrett's esophagus

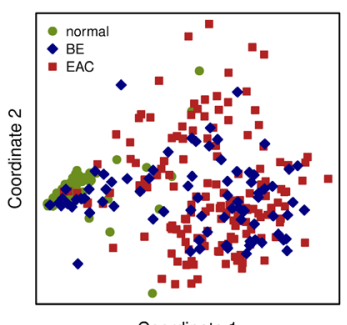

Coordinate 1

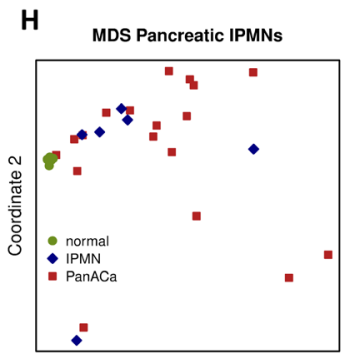

Coordinate 1

K

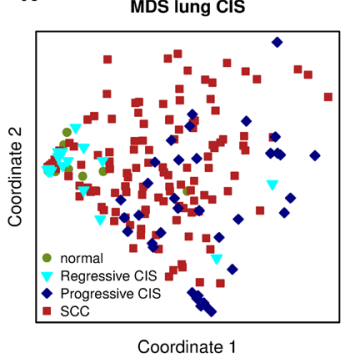

Figure 1. DNA methylation of the biomarker loci occurs early in carcinogenesis. The figure shows data from five primary carcinoma sites: breast $(\mathbf{A}, \mathbf{B})$, colorectal $(\mathbf{C}, \mathbf{D})$, esophagus $(\mathbf{E}, \mathbf{F})$, pancreas $(\mathbf{G}, \mathbf{H})$ and lung $(\mathbf{I}, \mathbf{J}, \mathbf{K})$. Boxplots $(\mathbf{A}, \mathbf{C}, \mathbf{E}, \mathbf{G}, \mathbf{I})$ show cumulative DNA methylation of the 10 biomarker loci in normal tissue samples, precancerous lesions, and tumor samples. The $y$-axes of plots represent the sums of beta values of the entire set of 10 biomarker CpG Illumina probes. The breast boxplots $(\mathbf{A})$ in addition show DNA methylation of the biomarker set in 44 pairs of primary breast tumors and lymph node metastases. The lung boxplots (I) in addition present the precancerous lesion (carcinoma in situ (CIS)) cohort split into progressive and regressive sub cohorts and lung tumor (squamous cell carcinoma (SCC)) cohort split into stages I-III. The multidimensional scaling (MDS) plots (B, D, F, H, K) show multidimensional scaling of pairwise distances derived from beta values of 10 biomarker $\mathrm{CpG}$ probes of the same sample cohorts as in the boxplots. The receiver operating characteristic $(R O C)$ plot $(\mathbf{J})$ shows that the cumulative DNA methylation of the 10 biomarkers can differentiate progressive lung CIS samples not only from normal lung tissue samples (blue curve), but also from regressive lung CIS samples (purple curve). DCIS, ductal CIS; IPMN, intraductal papillary mucinous neoplasm.

GSE7795422, GSE53051 ${ }^{19}$. Similar to DCIS, biomarker loci are already hypermethylated in colorectal adenomas with no further increase in methylation during the progression into invasive colorectal carcinomas or metastatic colorectal cancer (Figure 1C) and again colorectal adenomas on MDS plot are scattered among colorectal carcinomas (Figure 1D).

Barrett's esophagus is a precancerous precursor of esophageal adenocarcinoma (EAC). We analyzed normal esophagus together with BE and EAC samples from two GEO datasets: GSE72872 ${ }^{23}$, GSE8133424. Again, similar to DCIS or colorectal adenomas, biomarker loci are hypermethylated already in BE (Figure 1E, F). Similar situation was observed also in pancreatic intraductal papillary mucinous neoplasms (IPMNs), precursor lesions of pancreatic adenocarcinomas, where only one small dataset (GSE53051 ${ }^{19}$ ) was available (Figure 1G, H).

Finally, we analyzed lung CIS. Lung CIS is a pre-invasive precursor lesion of lung squamous cell carcinoma (SCC), one of the two non-small cell lung cancers that we previously used to demonstrate the capability of the biomarkers to distinguish between clinical plasma samples from cancer patients and healthy subjects. We analyzed DNA methylation of the biomarker loci in lung CIS together with lung SCC and normal lung tissue samples from GEO datasets GSE10812325, GSE39279 ${ }^{26}$. The advantage of the original lung CIS study (GSE10812325) is that the prospective follow-up information is available for CIS samples and thus the samples could be classified as either progressive 
(those later progressed into invasive cancer) or regressive (these later regressed to normal epithelium or low-grade disease). Our analysis revealed, similar to the other pre-invasive lesions, that the biomarker loci have increased DNA methylation already at the lung CIS stage (Figure 1I). More importantly, when we analyzed progressive and regressive lung CIS samples separately (Figure 1I), we found that the biomarker set is able to distinguish between the two types of premalignant lesions with high sensitivity and specificity (AUC $=0.92$, Figure $1 \mathrm{~J}$ ). The majority of the regressive lung CIS samples on the MDS plots cluster close to normal lung controls while all progressive lung CIS samples are scattered among lung SCC samples (Figure 1K). Even when lung SCC samples are sub-grouped into the individual cancer progression stages (I-III) there is no increase in DNA methylation with the stage (Figure 1I). Together, these results show that the gain of DNA methylation of the biomarker loci is an early epigenetic event during human carcinogenesis.

The data presented here show that DNA methylation of the biomarker loci is fundamentally changed early during the malignant progression since it is already observed in precancerous lesions. The data from lung CIS further show that the DNA methylation level of the biomarkers can differentiate between potentially malignant and benign CIS. Together, these findings indicate that the biomarkers are capable, from the qualitative point of view, to detect cancer at its earliest stages. However, the detection of cancer-specific DNA methylation in blood or other body fluids is quantitative in nature and depends on the tumor size and its propensity to shed DNA into bloodstream; e.g., our previous report $^{14}$ shows that the DNA methylation signal from this biomarker set in cfDNA samples depends on the NSCLC tumor size. Later disease stages are thus relatively easy to detect since larger tumors of later cancer stages shed a large amount of DNA into bloodstream resulting in high DNA methylation signal. In order to detect the early cancer stages as well, sensitive detection techniques and especially sample processing leading to minimal background DNA methylation signal will be profound to distinguish cancer from healthy samples. This report shows that the DNA methylation change of the biomarker loci is already present to its full extent in the earliest cancer stages. Thus, the combination of the sensitive detection and the timing of the release of enough tumor DNA into blood or other body fluids are the factors that will set the limit of the biomarkers to detect cancer early.

In conclusion, the biomarker loci have the potential to detect malignant disease at its earliest stage and the only limitation to the use of the biomarkers to detect cancer from liquid biopsies is the timing when the tumors start to release enough DNA into bloodstream.

\section{Data availability}

\section{Source data}

Illumina HumanMethylation450 DNA methylation data used in the presented study can be downloaded from the Gene Expression Omnibus database (https://www.ncbi.nlm.nih.gov/geo/; Accession numbers: GSE60185, GSE66313, GSE53051, GSE58999, GSE48684, GSE77954, GSE72872, GSE81334, GSE108123 and GSE39279).
1. Feinberg AP, Ohlsson R, Henikoff $S$ : The epigenetic progenitor origin of human cancer. Nat Rev Genet. 2006; 7(1): 21-33. PubMed Abstract | Publisher Full Text

2. Kulis M, Esteller M: DNA methylation and cancer. Adv Genet. 2010; 70: 27-56. PubMed Abstract | Publisher Full Text

3. Sina AA, Carrascosa LG, Liang Z, et al.: Epigenetically reprogrammed methylation landscape drives the DNA self-assembly and serves as a universal cancer biomarker. Nat Commun. 2018; 9(1): 4915. PubMed Abstract | Publisher Full Text | Free Full Text

4. Moss J, Magenheim J, Neiman D, et al:: Comprehensive human cell-type methylation atlas reveals origins of circulating cell-free DNA in health and disease. Nat Commun. 2018; 9(1): 5068 PubMed Abstract | Publisher Full Text | Free Full Text

5. Bettegowda C, Sausen M, Leary RJ, et al.: Detection of circulating tumor DNA in early- and late-stage human malignancies. Sci Trans/ Med. 2014; 6(224): 224 ra24.

PubMed Abstract | Publisher Full Text | Free Full Text

6. Jahr S, Hentze H, Englisch S, et al.: DNA fragments in the blood plasma of cancer patients: quantitations and evidence for their origin from apoptotic and necrotic cells. Cancer Res. 2001; 61(4): 1659-65.

PubMed Abstract

7. Snyder MW, Kircher M, Hill AJ, et al.: Cell-free DNA Comprises an In Vivo Nucleosome Footprint that Informs Its Tissues-Of-Origin. Cell. 2016; 164(1-2): $57-68$.

PubMed Abstract | Publisher Full Text | Free Full Text

8. Schwarzenbach $\mathrm{H}$, Hoon DS, Pantel $\mathrm{K}$ : Cell-free nucleic acids as biomarkers in cancer patients. Nat Rev Cancer. 2011; 11(6): 426-37. PubMed Abstract | Publisher Full Text

9. Wan JCM, Massie C, Garcia-Corbacho J, et al.: Liquid biopsies come of age: towards implementation of circulating tumour DNA. Nat Rev Cancer. 2017; 17(4): 223-38.

PubMed Abstract | Publisher Full Text
10. Fackler MJ, Lopez Bujanda Z, Umbricht C, et al:: Novel methylated biomarkers and a robust assay to detect circulating tumor DNA in metastatic breast cancer. Cancer Res. 2014; 74(8): 2160-70. PubMed Abstract | Publisher Full Text | Free Full Text

11. Grutzmann R, Molnar B, Pilarsky C, et al.: Sensitive detection of colorectal cancer in peripheral blood by septin 9 DNA methylation assay. PLOS One. 2008; 3(11): e3759.

PubMed Abstract | Publisher Full Text | Free Full Text

12. Uehiro N, Sato F, Pu F, et al.: Circulating cell-free DNA-based epigenetic assay can detect early breast cancer. Breast Cancer Res. 2016; 18(1): 129. PubMed Abstract | Publisher Full Text | Free Full Text

13. Vrba L, Futscher BW: A suite of DNA methylation markers that can detect most common human cancers. Epigenetics. 2018; 13(1): 61-72. PubMed Abstract | Publisher Full Text | Free Full Text

14. Vrba L, Oshiro MM, Kim SS, et al:: DNA methylation biomarkers discovered in silico detect cancer in liquid biopsies from non-small cell lung cancer patients. Epigenetics. 2019; 1-12. PubMed Abstract | Publisher Full Text

15. Team RC: R: A Language and Environment for Statistical Computing. Vienna, Austria: R Foundation for Statistical Computing. 2019. Reference Source

16. Robin X. Turck N, Hainard A, et al.: pROC: an open-source package for R and S+ to analyze and compare ROC curves. BMC Bioinformatics. 2011; 12: 77 PubMed Abstract | Publisher Full Text | Free Full Text

17. Fleischer T, Frigessi A, Johnson KC, et al:: Genome-wide DNA methylation profiles in progression to in situ and invasive carcinoma of the breast with impact on gene transcription and prognosis. Genome Biol. 2014; 15(8): 435 . 15(8): 435.
PubMed Abstract | Publisher Full Text | Free Full Text

18. Johnson KC, Koestler DC, Fleischer T, et al: DNA methylation in ductal carcinoma in situ related with future development of invasive breast cancer. 
Clin Epigenetics. 2015; 7: 75.

PubMed Abstract | Publisher Full Text | Free Full Text

19. Timp W, Bravo HC, McDonald OG, et al.: Large hypomethylated blocks as universal defining epigenetic alteration in human solid tumors. Genome Med. 2014; 6(8): 61

PubMed Abstract | Publisher Full Text | Free Full Text

20. Reyngold M, Turcan S, Giri D, et al.: Remodeling of the methylation landscape in breast cancer metastasis. PLoS One. 2014; 9(8): e103896.

PubMed Abstract | Publisher Full Text | Free Full Text

21. Luo Y, Wong CJ, Kaz AM, et al:: Differences in DNA methylation signatures reveal multiple pathways of progression from adenoma to colorectal cancer. Gastroenterology. 2014; 147(2): 418-29.e8.
PubMed Abstract | Publisher Full Text | Free Full Text

22. Qu X, Sandmann T, Frierson $\mathrm{H}$ Jr, et al:: Integrated genomic analysis of colorectal cancer progression reveals activation of EGFR through demethylation of the EREG promoter. Oncogene. 2016; 35(50): 6403-6415. PubMed Abstract | Publisher Full Text | Free Full Text
23. Krause L, Nones K, Loffler KA, et al.: Identification of the CIMP-like subtype and aberrant methylation of members of the chromosomal segregation and spindle assembly pathways in esophageal adenocarcinoma. Carcinogenesis. 2016; 37(4): 356-65.

PubMed Abstract | Publisher Full Text | Free Full Text

24. Yu M, Maden SK, Stachler M, et al.: Subtypes of Barrett's oesophagus and oesophageal adenocarcinoma based on genome-wide methylation analysis. Gut. 2018; 68(3). pii: gutjnl-2017-314544. PubMed Abstract | Publisher Full Text | Free Full Text

25. Teixeira VH, Pipinikas $\mathrm{CP}$, Pennycuick $\mathrm{A}$, et al.: Deciphering the genomic, epigenomic, and transcriptomic landscapes of pre-invasive lung cancer lesions. Nat Med. 2019; 25(3): 517-25. PubMed Abstract | Publisher Full Text

26. Sandoval J, Mendez-Gonzalez J, Nadal E, et al.: A prognostic DNA methylation signature for stage I non-small-cell lung cancer. J Clin Oncol. 2013; 31(32): 4140-7.

PubMed Abstract | Publisher Full Text 


\section{Open Peer Review}

\section{Current Peer Review Status:}

\section{Version 1}

Reviewer Report 24 January 2020

https://doi.org/10.5256/f1000research.23787.r57862

(C) $\mathbf{2 0 2 0}$ Rice J. This is an open access peer review report distributed under the terms of the Creative Commons Attribution License, which permits unrestricted use, distribution, and reproduction in any medium, provided the original work is properly cited.

Judd C. Rice

Department of Biochemistry and Molecular Medicine, Keck School of Medicine, University of Southern California, Los Angeles, CA, USA

In this brief report by Vrba and Futscher, the authors sought to leverage their previous discovery of 10 cancer-associated DNA methylation biomarker loci to investigate the clinical potential of these biomarkers in assessing the progression of carcinogenesis. The authors analyzed several publicly available datasets that included normal tissue, precancerous lesions and tumor samples to generate in silico models of breast, colorectal, esophageal, pancreatic and lung cancer progression. The rigor of the study design is high as all datasets utilized the same technology (Illumina HumanMethylation450) with appropriate sample size of each group for analysis, except for the pancreatic samples. Although the data presented support the authors' conclusions, at least by the eyeball test, the inclusion and description of detailed statistical analyses would increase confidence in the conclusions. The overall results indicate that aberrant methylation of the biomarker loci is an early epigenetic event of carcinogenesis, regardless of cancer type. This is an important finding that further supports the clinical potential of DNA methylation biomarkers in early cancer detection.

Is the work clearly and accurately presented and does it cite the current literature? Yes

Is the study design appropriate and is the work technically sound? Yes

Are sufficient details of methods and analysis provided to allow replication by others? Yes

If applicable, is the statistical analysis and its interpretation appropriate? Yes

Are all the source data underlying the results available to ensure full reproducibility? 
Yes

Are the conclusions drawn adequately supported by the results?

Yes

Competing Interests: No competing interests were disclosed.

Reviewer Expertise: Epigenetics.

I confirm that I have read this submission and believe that I have an appropriate level of expertise to confirm that it is of an acceptable scientific standard.

Author Response 11 Feb 2020

Lukas Vrba

Dear Dr. Rice, Thank you for the evaluation of our study. According to your suggestion and suggestion from the other reviewer we added the p-values to Figure 1. The results now show that all the differences that made the "eyeball test" are also highly statistically significant, including in the pancreatic samples where the $\mathrm{n}$ is rather low but the control cohort is consistently unmethylated. We thank you for this suggestion, since the amended version of our manuscript will have higher impact among the readers.

Competing Interests: No competing interests were disclosed.

Reviewer Report 08 January 2020

https://doi.org/10.5256/f1000research.23787.r57865

(c) 2020 Robertson K. This is an open access peer review report distributed under the terms of the Creative Commons Attribution License, which permits unrestricted use, distribution, and reproduction in any medium, provided the original work is properly cited.

\section{Keith D. Robertson}

Department of Molecular Pharmacology and Experimental Therapeutics, Mayo Clinic, Rochester, MN, USA

In this manuscript, Vrba and Futscher examined the DNA methylation status of candidate loci in pre-malignant stages of a variety of cancers (e.g. breast, pancreas, and esophagus). Ultimately, the authors observed that DNA hypermethylation events previously identified in full-blown cancer were already hypermethylated in the precancerous tissues. One particularly interesting outcome was that progressive lung carcinoma in situ demonstrated elevated methylation levels, while regressive CIS more closely resembled normal lung tissue, suggesting that these CpGs may actually be predictive of progression and/or play a role in carcinogenesis. 
This is a straight-forward in silico analysis study, and seems worthy of indexing since the methylation biomarker field is moving rapidly and showing significant promise.

This reviewer has two concerns, however, that should be addressed:

1. While the methylation trends are clearly qualitatively visible, statistical significance is not given for any of the comparisons.

2. Due to pre-malignant lesions showing similar patterns as the corresponding cancer, does that reduce the efficacy of these biomarkers as the target screening population malignancy is indistinguishable from the cancer? For example, healthy individuals are not routinely screened for esophageal carcinoma, but those with Barrett's esophagus are.

Is the work clearly and accurately presented and does it cite the current literature? Yes

Is the study design appropriate and is the work technically sound?

Yes

Are sufficient details of methods and analysis provided to allow replication by others? Yes

If applicable, is the statistical analysis and its interpretation appropriate? Yes

Are all the source data underlying the results available to ensure full reproducibility? Yes

Are the conclusions drawn adequately supported by the results?

Yes

Competing Interests: No competing interests were disclosed.

I confirm that I have read this submission and believe that I have an appropriate level of expertise to confirm that it is of an acceptable scientific standard.

Author Response 11 Feb 2020

Lukas Vrba

Dear Dr. Robertson,

Thank you for the prompt and generally positive review of our article. We have postponed our response until all reviews were available and a new version of the article was submitted.

As to the first point raised, the other reviewer had the same suggestion and therefore we added $p$-values for comparisons of individual sample cohorts. All differences between normal tissues and respective premalignant lesions are highly statistically significant, while 
there are no significant differences in DNA methylation of the biomarker loci during further malignant progression.

We especially appreciate your second point. The presence of the increased DNA methylation at marker loci may indeed raise doubts about how well the biomarkers may serve for cancer screening of individuals with premalignant conditions. We think that it depends on the type of the samples used for the screening (liquid vs tissue biopsies) and we have added the whole new paragraph discussing this topic. We thank you for raising this important point since it had to be discussed to make the study complete.

Competing Interests: No competing interests were disclosed.

The benefits of publishing with F1000Research:

- Your article is published within days, with no editorial bias

- You can publish traditional articles, null/negative results, case reports, data notes and more

- The peer review process is transparent and collaborative

- Your article is indexed in PubMed after passing peer review

- Dedicated customer support at every stage

For pre-submission enquiries, contact research@f1000.com 